(c) American Dairy Science Association, 2003.

\title{
Keeping Science in Environmental Regulations: The Role of the Animal Scientist
}

\author{
W. J. Powers \\ Department of Animal Science, lowa State University
}

\begin{abstract}
Environmental issues continue to be one of the biggest challenges faced by livestock producers. Whereas issues of the past have focused on manure nutrient impacts on water quality with some regulatory activity addressing odors, emerging issues are more diverse. To address emerging air quality issues, such as ammonia emissions, antibiotic transfer, human health impacts of emissions from animal agriculture, and estrogens in the environment, scientists with expertise in physiology, genetics, animal management, and nutrition will need to be enlisted. The objectives of this review are to highlight some of the prominent environmental regulatory activity that has occurred nationally in the past few years, to outline some of the emerging environmental issues, and to move members of the animal science profession toward thinking about what they can contribute toward addressing these issues. Animal scientists are uniquely qualified to engage in environmental research, education, and policymaking because of our comprehensive understanding of the complexity of whole-farm management and the interactions between animal management and manure management. Animal science departments have the opportunity to train students to be leaders in addressing environmental issues related to animal production, provided departments incorporate environmental education into curricula. Animal scientists can contribute greatly to the many areas of research that address emerging and current environmental issues, helping to ensure that policy is science-based and mitigation strategies are feasible. (Key words: environment, regulation, air quality, animal science curricula)
\end{abstract}

\begin{abstract}
Abbreviation key: $\mathbf{A U}=$ animal unit, $\mathbf{C A F O}=$ Concentrated Animal Feeding Operations, EPA = United States Environmental Protection Agency, $\mathbf{P M}=$ particulate matter.
\end{abstract}

Received August 7, 2002.

Accepted October 11, 2002.

Corresponding author:W.J. Powers; e-mail:wpowers@iastate.edu.

\section{INTRODUCTION}

Greater emphasis is now placed on multidisciplinary problem solving. With that in mind, it is no wonder that animal scientists are becoming more involved in environmental issues than ever before. The animal scientist can contribute greatly to issues spanning animal production and the environment. Nutrition has typically served as the animal science discipline most likely to address the environment because of the obvious association with feeding practices and nutrient excretion. However, as environmental regulations become more restrictive and include issues beyond traditional manure management, a broader range of animal science disciplines will be needed to address pending challenges. Regulations and compliance solutions that are reasonable and achievable rely on the active involvement of a broad range of scientists, including animal scientists with varied specializations.

\section{CURRENT STATE AND FEDERAL REGULATORY ACTIVITIES}

Much activity has taken place in recent years concerning environmental regulations for the livestock industry. Things have slowed little in the past $12 \mathrm{mo}$. Currently, the Environmental Protection Agency (EPA) is preparing to release revisions to the Clean Water Act that apply to Concentrated Animal Feeding Operations (CAFO). These operations represent the larger operations, currently over 1000 animal units (AU; where $1 \mathrm{AU}$ is equivalent to a $454 \mathrm{~kg}$ of beef animal), plus some smaller operations that pose an environmental risk. The revisions are expected to be complete by the end of 2002. Whereas it is difficult to predict what final revisions will include, some issues have been repeatedly discussed as part of the proposed revisions since the process began in 1995 . Specific changes proposed include

- Redefining the CAFO definition such that more operations will be designated as CAFO. Specific proposals include

- Lowering AU requirements to as low as 500 $\mathrm{AU}$ from the current $1000 \mathrm{AU}$, where $1 \mathrm{AU}$ is equivalent to a $454 \mathrm{~kg}$ of beef animal. An alter- 
nate proposal is to keep the CAFO designation at $1000 \mathrm{AU}$ and include some farms between 300 and $1000 \mathrm{AU}$ that pose exceptional risk to the environment due to location or previous violations.

- Expand CAFO classification beyond liquid systems to include dry manure-handling operations, such as poultry.

- Having immature animal operations (swine nurseries and heifer and veal operations) as CAFO if they meet the designated size threshold.

- Elimination of the 25-yr, 24-h storm permit exemption that excludes large farms from receiving CAFO designation if they only discharge during a 25-yr, 24-h storm event. Elimination of this exemption eliminates protection in the event of a catastrophic storm.

- Requiring covered storage of swine and poultry wastes to prevent precipitation or storm water addition to storage structures and to minimize emissions from these structures.

- Requiring liners in storage lagoons on beef and dairy farms that have a hydrologic link between ground water and surface water.

- Requiring that contractors with the primary decision-making responsibilities obtain permits to share liability with their producers.

- Instilling greater emphasis on nutrient management by requiring all CAFO to have a site-specific Permit Nutrient Plan and by moving all plans towards phosphorus-based manure application rates.

- Increased record-keeping and inspection requirements for CAFO.

As a result, a greater number of operations will be designated as CAFO if any or all of the above proposals are adopted. The operation size threshold for each species for determining which operations will be designated as CAFO is still undecided. The most recent Notice of Data Availability issued by the EPA in July 23, 2002 (Federal Register: 67:48099-48110), solicited comments on how best to determine species equivalency, particularly with respect to poultry. Regardless of the final outcome, all CAFO will be held to a higher standard by the new requirements than under the current regulations. Therefore, there will be some cost for compliance for many, if not most, producers and in some cases, compliance will be determined to be unaffordable. In many cases, manure management practices will change, and it is essential that these changes complement and coordinate with animal production practices. Interaction of those with expertise in animal pro- duction with those making decisions regarding environmental management is critical.

For the past several years, much of the activity addressing environmental issues associated with animal production have focused on the revision of the Clean Water Act via the USEPA/USDA Joint Strategy for Animal Feeding Operations. However, as the strategy has evolved we have seen discussion on air quality within the proposed documents. In a Notice of Data Availability for the proposed rule (Federal Register, November 21, 2001) the EPA lists as one of its specific 19 points for which comment was requested: "approaches it is considering for the quantification and monetization of changes in air emissions resulting from the regulation...”. Clearly the move towards addressing air quality impacts of animal feeding operations has gained momentum as a result of nuisance and human health concerns. In the Clean Air Act amendments of 1990, the EPA was required to establish National Ambient Air Quality Standards for pollutants considered harmful to human health. As a result, primary standards were established to protect public health while secondary standards were established to protect public welfare (e.g., decreased visibility, damage to crops, animals, buildings). In addition to gaseous emissions, particulate matter (PM) was included in the standards. Standards were established for six criteria pollutants $\left(\mathrm{CO}, \mathrm{NO}_{2}, \mathrm{O}_{3}, \mathrm{~Pb}, \mathrm{PM}_{10}\right.$, and $\mathrm{SO}_{2}$ ). In 1997, the Clean Air Act was amended, and a new criteria pollutant was proposed, $\mathrm{PM}_{2.5}$. However, a 1999 federal court ruling blocked the implementation of this addition citing an unconstitutional delegation of legislative power. Despite this setback, regulation of $\mathrm{PM}_{2.5}$ is in the foreseeable future. As the EPA winds down its efforts on the Clean Water Act, it is highly likely that revision of the Clean Air Act will follow. As a result of this activity, it is expected that regulation of fine particulates will resurface again in the next proposed revision. Ammonia emissions are indirectly related to PM. Particulate matter poses perhaps the greatest challenge for animal agriculture. Direct emission sources of $\mathrm{PM}_{10}$, the coarse particulates, arise primarily from combustion processes (Figure 1; EPA, 1998). Direct emissions of $\mathrm{PM}_{2.5}$, respirable particulates, are also primarily the result of combustion processes (Figure 2; EPA, 1998). In addition to direct emissions, secondary processes, whereby $\mathrm{SO}_{\mathrm{x}}$ or $\mathrm{NO}_{\mathrm{x}}$ and $\mathrm{NH}_{3}$ react in the atmosphere to form ammonium sulfate and ammonium nitrate fine particles, contribute to as much as half of the $\mathrm{PM}_{2.5}$ measured in the United States. The EPA estimates that $86 \%$ of the national ammonia emissions are from miscellaneous sources that include livestock and fertilizer (Figure 3; EPA, 1998). Livestock agriculture accounted for $83 \%$ of all emissions in the miscellaneous category with fertil- 


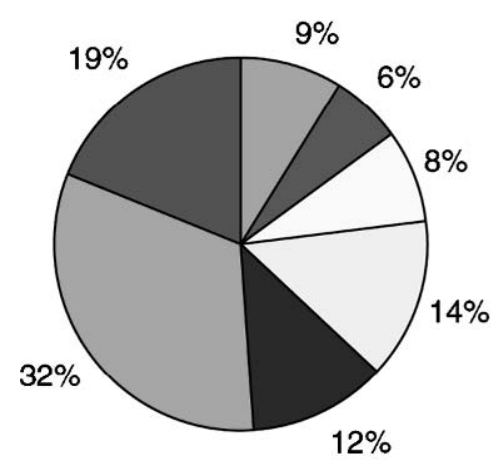

\begin{tabular}{|c|}
$\square$ Other Industrial \\
Processes - 9\% \\
$\square$ Fuel Combustion - \\
Industrial - 6\% \\
$\square$ Fuel Combustion - \\
Electrical Utility - 8\% \\
$\square$ Fuel Combustion - \\
Other - 14\% \\
$\square$ All Other - 12\% \\
$\square$ Area Source \\
Combustion - 32\% \\
$\square$ On-Road and Non- \\
Road Engines and \\
Vehicles - 19\%
\end{tabular}

Figure 1. 1998 directly emitted national particulate matter $\left(\mathrm{PM}_{10}\right)$ emissions by principal source categories for nonfugitive dust sources (EPA, 1998).

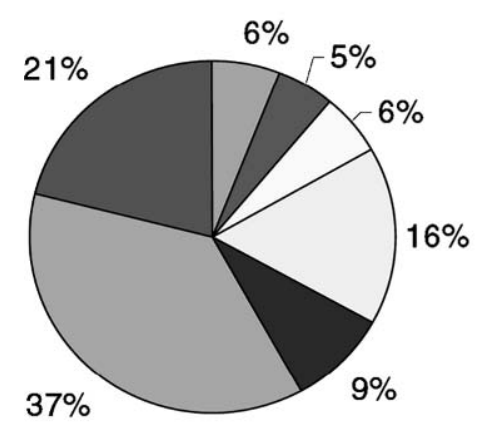

\begin{tabular}{|l|}
\hline Other Industrial \\
Processes - 6\% \\
$\square$ Fuel Combustion - \\
Industrial - 5\% \\
$\square$ Fuel Combustion - \\
Electrical Utility - 6\% \\
$\square$ Fuel Combustion - \\
Other - 16\% \\
$\square$ All Other - 9\% \\
$\square$ Area Source \\
Combustion - 37\% \\
$\square$ On-Road and Non- \\
Road Engines and \\
Vehicles - 21\%
\end{tabular}

Figure 2. 1998 Directly emitted national particulate matter $\left(\mathrm{PM}_{2.5}\right)$ emissions by principal source categories for nonfugitive dust sources (EPA, 1998).

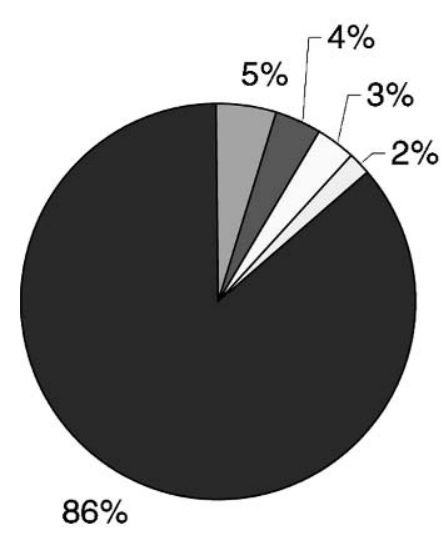

\begin{tabular}{|l}
\hline On-Road and Non- \\
Road Engines and \\
Vehicles - 5\% \\
$\square$ All Other - 4\% \\
$\square$ Chemical \& Allied \\
Product Mfg. - 3\% \\
$\square$ Waste Disposal \& \\
Recycling - 2\% \\
$\square$ Misc. (includes \\
livestock and \\
fertilizer) - 86\%
\end{tabular}

Figure 3. 1998 National ammonia emissions by principal source categories (EPA, 1998).

izer application comprising the remainder. The EPA already regulates many combustion processes through industrial and utility permitting processes. Area sources are not likely to be targeted for future regulation because they are nonpoint source emitters. To address particulate emission reductions, animal agriculture is a likely target due to its contribution to ammonia emissions that, in turn, can contribute up to half of particulate concentrations and emissions. The National Academy of Science's Committee on Animal Nutrition released a preliminary report in June 2002 entitled "The Scientific Basis for Estimating Air Emissions from Animal Feeding Operations" that illustrates the United States' interest in air quality surrounding livestock operations. A final report, due in late 2002 will be available from the National Academy of Science's website. Animal agriculture must be taking steps to address ammonia production and emission. In 1984 legislation was enacted in The Netherlands to reduce 2000 ammonia emissions by $50 \%$ relative to 1980 emissions (Lenis and Jongbloed, 1999). Such requirements here in the United States could change animal agriculture, both structure and management, dramatically.

\section{State Air Quality Activity}

A number of states have initiated efforts to address air emissions from animal feeding operations. Missouri, for example, has restricted odor emissions from CAFO. The regulation (Missouri Department of Natural Resources Division 10 Air Conservation Commission, Chapter 3, Title 10 CSR 10-3.090) requires that all CAFO implement odor control plans, effective January 1, 2002, that has been approved by the Air Pollution 
Control Program. Any CAFO must not emit odors that exceed an odor threshold of 5.4 (five and four-tenths parts of odor-free air with one part of odorous air) as determined by use of a Scentometer (Barnebey \& Sutcliffe Corporation, Columbus, OH). This serves as a screening tool at the site. If that threshold is exceeded, further measurements using olfactometry will ensue. This regulation has not been without controversy. On December 6, 2001, the Missouri Air Conservation Commission decided that due to concerns regarding the stringency of the detection threshold standard, violations to that standard would not be issued until more research was conducted. However, the odor plan component of the rule remained unaffected by the commission's decision.

In 1997, the California South Coast Air Quality Management District (SCAQMD) established emission reduction goals for animal agriculture within its area in response to nonattainment of $\mathrm{PM}_{10}$ and ozone standards (CM\#99WST-01 Appendix B: New and Revised Stationary Source Control Measures). The SCAQMD has set a goal of $30 \%$ reduction of volatile organic carbon emissions from livestock waste by 2006 and 50\% reduction of ammonia emissions from dairy operations by 2006. One of the primary mechanisms for reaching the stated ammonia goal is relocation of the dairy industry out of the area. However, if the targets are not met by January 1, 2004, dairy and other livestock facilities still located in the Basin will be subject to ammonia controls. Possible controls include reduced nitrogen feeding, promotion of aerobic manure storage condition, including use of enzymes and microbial products, off-site composting, and chemical alteration of manure $\mathrm{pH}$.

The state of Colorado approved Amendment 14 in 1998, requiring the Air Quality Control Commission to develop regulations for commercial housed swine operations. Following air quality Regulation No. 2, Part B was promulgated in February 1999, and all existing and new hog operations were required to be in compliance by July 1,1999 . This regulation requires that an odor standard of 7:1 dilutions be met at and beyond the operation's property line and an odor standard of 2:1 dilutions be met at any receptor. Measurements are made using a scentometer. Certified personnel of a third party vendor or the state health department conduct measurements twice annually. Measurements are made once in either January or February and once in either July or August. The regulation also requires that all new, expanded, and existing anaerobic storages be covered. The third component of the regulation requires a one-mile setback from all occupied dwellings, schools, and municipality boundaries for manure application site and manure storage sites.
In 1999, the state of Minnesota implemented a hydrogen sulfide standard as an indicator of odor. Minnesota's standard is a 30-min average of $30 \mu \mathrm{g} / \mathrm{kg}$ twice in $5 \mathrm{~d}$, or a 30 -min average of $50 \mu \mathrm{g} / \mathrm{kg}$ twice per year. More recently, the Minnesota Department of Health has begun to consider adoption of inhalation standards for hydrogen sulfide that are health-based rather than nuisance-based standards.

In 2002 the state of Iowa also adopted standards for hydrogen sulfide and ammonia at a residence neighboring a CAFO. Odor standards were considered but not adopted because of a tenuous association in the literature between exposure to livestock odors and negative health impacts. Under Senate File 2293 the state Department of Natural Resources will conduct a comprehensive field study to monitor the level of airborne pollutants, particularly hydrogen sulfide, ammonia, and odor, emitted from animal feeding operations in the state. Consequently, the department may develop comprehensive plans and programs for the abatement, control, and prevention of airborne pollutants, if the baseline data from the field study demonstrate, to a reasonable degree, that airborne pollutants emitted by an animal-feeding operation are present downwind, at levels commonly known to cause a material and verifiable adverse health effect. Enforcement of an air quality standard will not occur before December 1, 2004. Any air quality standard established will rely on measurements taken at the separated distance. This regulation is based on human health impacts of emissions from animal-feeding operations and should reflect exposure levels consistent with negative impacts under chronic exposure ( $>365 \mathrm{~d}$ ). Therefore, measurements should be taken where chronic exposure conditions will occur. A report released by the University of Iowa and Iowa State University in February 2002 adopts the Agency for Toxic Substances Disease Registry's recommendations for hydrogen sulfide and ammonia chronic ( $>365$ d) exposures. These numbers correspond to $15 \mu \mathrm{g} / \mathrm{kg}$ hydrogen sulfide and $150 \mu \mathrm{g} / \mathrm{kg}$ ammonia. The committee did not reach consensus on an odor recommendation.

To date, most of the state regulatory discussions regarding air emissions from animal agriculture have focused on odor concerns. While odor has generally been considered a nuisance, there is considerable interest in determining the human health impacts of emissions, including odor from livestock operations, particularly confinement operations. Some states have pursued this issue through state and local boards of health. In addition, the EPA has commissioned the National Academy of Science to conduct a study investigating the state of the science on this issue. The findings of this study are expected to be released late in 2002 . While the research 
is limited, the continued rise in number of people afflicted with asthma (Weiss et al., 2000) and the perceived notion that something that smells offensive "can't be good for you" will propel the issue. Producers must be kept aware that in addition to worker safety issues, as overseen by the Occupational Safety and Health Administration, concerns over downwind human health impacts will not go away anytime soon and, in fact, will likely draw greater attention.

\section{EMERGING ENVIRONMENTAL CHALLENGES}

Beyond the items previously mentioned, other topics remain on the "radar screen" of state and federal regulatory agencies. Pathogens, antibiotic residues, endocrine disruptors, and global warming are just a few issues that have implications for animal agriculture and to date have not been the subject of much, if any, regulation. Food safety has received a tremendous amount of attention, and while we have a safe food supply in the United States, securing our food from any source of threat will continue to be a critical priority for consumers. While more recent events have raised awareness of the potential implications of agroterrorism, instances where food and water supplies have been compromised, possibly due to agricultural practices and pathogens emitted as a result of livestock production, have not been forgotten.

Several publications suggest the potential development of antibiotic resistance as a result of consumption of animal products thereby raising further scrutiny of the industry (D'Aoust et al., 1992; Arvanitidou et al., 1998; Manie et al., 1999). In addition, limited and unduplicated data suggest that antibiotics are emitted from animal facilities. Zahn et al. (2001) reported tylosin concentrations at the exhaust fan of swine finishing barns in the range of $8.1 \pm 5.3 \mathrm{ng} / \mathrm{L}$ of exhausted air. Given a common feed addition of $20 \mathrm{~g}$ of tylosin per ton of feed and average year-round air exchange rates for a mechanically ventilated swine finisher in Iowa, these data suggest that approximately $30 \%$ of the administered dose is exhausted from the building in an active form. While those data are limited and not duplicated, the implications could lead to some regulatory activity in the future, despite broad-scale efforts to reduce subtherapeutic and therapeutic use of antibiotics in the animal industry.

The effects of endocrine disruptors on fish and bird populations have been widely studied. Regulation of pesticides took place in the 1970s and 1980s to minimize the prevalence of endocrine disruptors in the environment. The topic of endocrine disruptors is currently not as prominent as it was $25 \mathrm{yr}$ ago. However, the proposed CAFO regulations do mention endocrine disruptors,

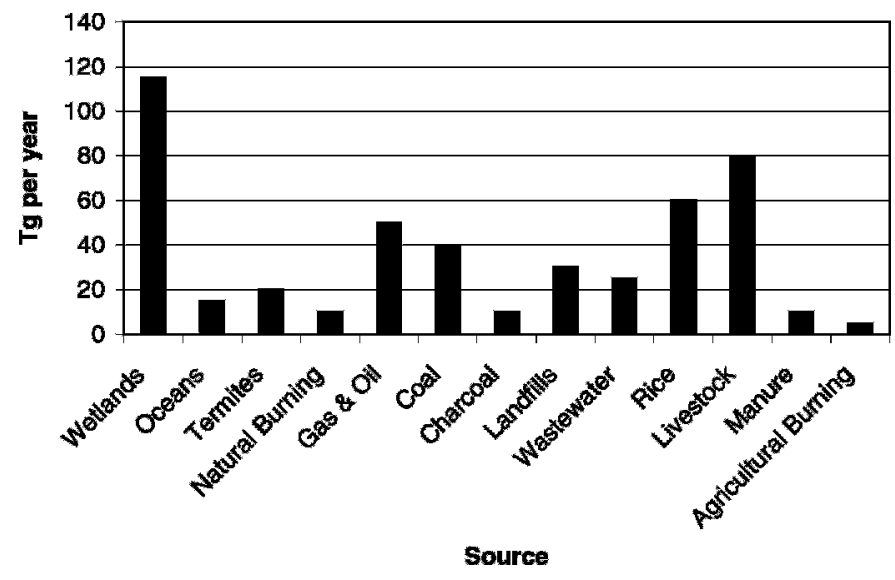

Figure 4. Natural and anthropogenic global methane sources, $(\mathrm{Tg} /$ yr). Tg = 1 million metric tons. (Johnson and Johnson, 1995).

leading one to suspect that the topic is not entirely out of the EPA's mind. Some recent work has investigated the presence and concentrations of estrogens associated with animal excretions and land application of animal manures. Where results indicated that grazing animals did not contribute estradiol or testosterone to runoff, compared with hayed plots, when poultry litter was applied, runoff concentrations of estradiol and testosterone increased as much as 15 -fold, relative to background concentrations of 50 to $150 \mathrm{ng} / \mathrm{L}$ estradiol and 15 to $125 \mathrm{ng} / \mathrm{L}$ testosterone, depending on litter application rate and time lapsed between application and the runoff event (Finlay-Moore et al., 2000). In the future, it is plausible that performance standards for excretion of estrogenic compounds will be considered. To meet such standards, evaluation of breeding and estrus synchronization programs may be necessary, requiring the involvement of reproductive physiologists.

Even though the United States has not signed the Kyoto treaty, there is considerable interest in reducing greenhouse gas emissions in the United States. Johnson and Johnson (1995) report that $67 \%$ of global greenhouse gas emissions are from anthropogenic sources with livestock contributing $17 \%$ of the total emissions from natural and anthropogenic sources combined (Figure 4). Ruminant livestock produce 250 to $500 \mathrm{~L}$ of methane per day (Johnson and Johnson, 1995), potentially accounting for $2 \%$ of the global warming that may occur in the next 50 to $100 \mathrm{yr}$. In addition to emissions as a result of eructation in ruminants, methane results from the anaerobic decomposition of manure during storage. So, it is not surprising when the suggestion is made that one area in which reductions should be focused is in animal agriculture. The Iowa Greenhouse Gas Action Plan (Ney et al., 1996) proposes that animal agriculture be the primary focus in the state's effort to 
reduce greenhouse gas emissions. The introduction of ionophores into ruminant diets has made considerable gains towards reducing methane emissions from beef and growing dairy cattle. If approved for use in lactating animals, greater reduction in total methane emission from the animal industry is eminent. New research efforts continue to identify methods of reducing methanogenic activity in the rumen without compromising animal performance. Findings by Miller and Wolin (2001) suggest that human drugs prescribed to lower cholesterol can reduce methane emissions and improve the efficiency of feed utilization. The acceptance of these drugs as feed additives will require a great deal more research before approval by the Food and Drug Administration because they are currently used by a small percentage of the population on a prescription basis, and long-term effects of product consumption from animals fed these drugs is yet undetermined. However, if methane emissions are regulated for animal agriculture, such research may be viable in the future. Besides methane, other greenhouse gases result from animal agriculture activities as well. Nitrous oxide is a product of organic matter, i.e., manure, decomposition. Recent data from Harper et al. (2000) suggest that as much nitrogen in the form of $\mathrm{N}_{2}$ is lost off of manure storages as in the form of ammonia. Because of difficulty in measuring volatilized nitrogen and its forms directly, most work has calculated $\mathrm{N}$ losses from inputs and remaining $\mathrm{N}$ and assumed that the $\mathrm{N}$ lost was in the form of ammonia. So, while we are overestimating ammonia emissions from animal production, we may be underestimating animal agriculture's contribution to greenhouse gas emissions. As regulations develop, so too, must measurement techniques.

The day may come when animal agriculture is targeted as a primary contributor to environmental pollution beyond nitrogen, phosphorus, and odor. Each of the above mentioned areas could, and likely will, be addressed to some extent using postexcretion strategies. In the case of methane emissions, nutritional methods to reduce methane escape from the animal or methane production in the manure can be implemented. Similarly, nutritional strategies can help curtail the precursors to nitrous oxide and ammonia. However, additional strategies will be needed to reduce excretion of pollutants that are not nutrients, such as hormones, pathogens, and antibiotic residue. Physiology, microbiology, and animal management specialists will be needed for these efforts. In addition to developing strategies to reduce pollution potential, there is also a great need to develop and refine measurement techniques for ambient concentrations of these pollutants as well as development of procedures to identify sources of pollutants.

\section{ANIMAL SCIENCE AND THE ENVIRONMENT}

Compliance with current, pending, and future regulations will impact all producers in some manner. Some producers will choose to exit the business rather than alter practices and implement controls. For those who choose to remain in animal production, guidance will be needed to ensure that practices to address environmental issues do not negatively interact with production practices. Agronomists and agricultural engineers have been key players in environmental issues in the past. In the future, these groups will continue to play an important role. However, there may be increased emphasis on preexcretion prevention than in the past, where the focus has been on postexcretion management. To date, preexcretion strategies have involved the nutritionist in an effort to reduce nitrogen and phosphorus content in the manure. However, many of the emerging issues will require expertise outside of nutrition. Animal scientists are well trained to assist in farm implementation strategies to address these emerging issues and in the process to develop suitable quantification methods. To prepare animal scientists for the future challenges posed by environmental concerns, we must be training our professionals such that we can participate in finding solutions that do not jeopardize the industry. Training at the undergraduate and graduate levels is a critical part of the process. Whereas many animal science curricula address environmental issues superficially, few delve into the detail needed to prepare undergraduates to work for regulatory agencies or as environmental managers for the livestock industry, and internship positions designed to provide necessary preparation are limited. Yet, it is in these types of positions that animal scientists can have the greatest impact. At the graduate level, preparation can be gained by crossdisciplinary training. However, animal science curricula need to allow sufficient breadth in the programs for students to gain sufficient exposure to other disciplines while retaining an animal science major. To be leaders in guiding policy, animal scientists must be positioned so that our input is sought by those making regulatory and policy decisions.

One of the biggest challenges faced with respect to environmental regulations is that oftentimes the regulation precedes the science. In the regulatory process itself, the regulation is passed, and then the rules are developed to enforce the regulation. In a perfect system, a checks and balances approach would be in place to ensure that regulations that are unattainable and immeasurable were not passed. This is not always the case. As a result, scientists and regulators end up struggling to find reasonable solutions for compliance and enforcement. At the air and watershed levels, it is diffi- 
cult to assess where pollution is coming from, and how much is emitted from each source, making enforcement a challenge unless emissions from a property line can be made and accurately assumed that pollution will result. Even when considering a single source at that source, it is often difficult to determine total air emissions without intensive, continuous monitoring. Methods to measure losses to air and water require further development to avoid estimating losses by difference. This has often been the case with nitrogen losses to the atmosphere. Nitrogen loss has been calculated as the difference between nitrogen input and nitrogen recovery. Lost nitrogen has typically been assumed to be lost as ammonia. However, as ammonia volatilization from animal feeding operations becomes a more prominent issue, the importance of knowing the speciation of volatilized nitrogen escalates. Quantification procedures at desired levels of detection then emerge as the challenge.

\section{CONCLUSIONS}

Production animal scientists are in the business of working towards more efficient production of a safe and nutritious food supply. Environmental stewardship is an inherent part of this effort. While past involvement in environmental issues by animal scientists has been effective, greater involvement by a broader range of expertise will be needed to comply with emerging issues that may become regulated at some point.

\section{REFERENCES}

Arvanitidou, M., A. Tsakris, D. Sofianou, and V. Katsouyannopoulos. 1998. Antimicrobial resistance and R-factor transfer of salmonellae isolated from chicken carcasses in Greek hospitals. Intl. J. Food. Microbiol. 40:197-201.

D’Aoust, J. Y., A. M. Sewell, E. Daley, and P. Greco. 1992. Antibiotic resistance of agricultural and foodborne Salmonella isolates in Canada: 1986-1989. J. Food Prot. 55:428-434.

EPA. 1998. National air pollutant emission trends, 1990-1998.

Finlay-Moore, O., P. G. Hartel, and M. L. Cabrera. 2000. 17 beta estradiol and testosterone in soil and runoff from grasslands amended with broiler litter. J. Environ. Qual. 29:1604-1611.

Harper, L. A., R. R. Sharpe, and T. B. Parkin. 2000. Gaseous nitrogen emissions from anaerobic swine lagoons: Ammonia, nitrous oxide, and dinitrogen gas. J. Environ. Qual. 29:1356-1365.

Johnson, K. A., and D. E. Johnson. 1995. Methane emissions from cattle. J. Anim. Sci. 73:2483-2492.

Lenis, N. P., and A. W. Jongbloed 1999. New technologies in low pollution swine diets; diet manipulation and use of synthetic amino acids, phytase and phase feeding for reduction of nitrogen and phosphorus excretion and ammonia emission. Asian-Australian J Anim. Sci. 12:305-327.

Manie, T., V. S. Brozel, W. J. Veith, and P. A. Gouws. 1999. Antimicrobial resistance of bacterial flora associated with bovine products in South Africa. J. Food Prot. 62:615-618.

Miller, T. L., and M. J. Wolin. 2001. Inhibition of growth of methaneproducing bacteria of the ruminant forestomach by hydroxymethylglutaryl-ScoA reductase inhibitors. J. Dairy Sci. 84:1445-1448.

Ney, R. A., J. L. Schnoor, N. S. J. Foster, and D. J. Forkenbrock. 1996. Iowa Greenhouse Gas Action Plan. A report for the Iowa Department of Natural Resources, Center for Global and Regional Environmental Research and Public Policy Center, Univ. Iowa, Iowa City, IA.

Weiss, K. B., S. D. Sullivan, and C. S. Lyttle. 2000. Trends in the cost of illness for asthma in the United States, 1985-1994. J. Allergy Clin. Immunol. 106:493-499.

Zahn, J. A., J. Anhalt, and E. Boyd. 2001. Evidence of transfer of tylosin and tylosin-resistant bacteria in air from swine production facilities using sub-therapeutic concentrations of tylan in feed. J. Anim. Sci. 79(Suppl.1):783. Abstr.). 